
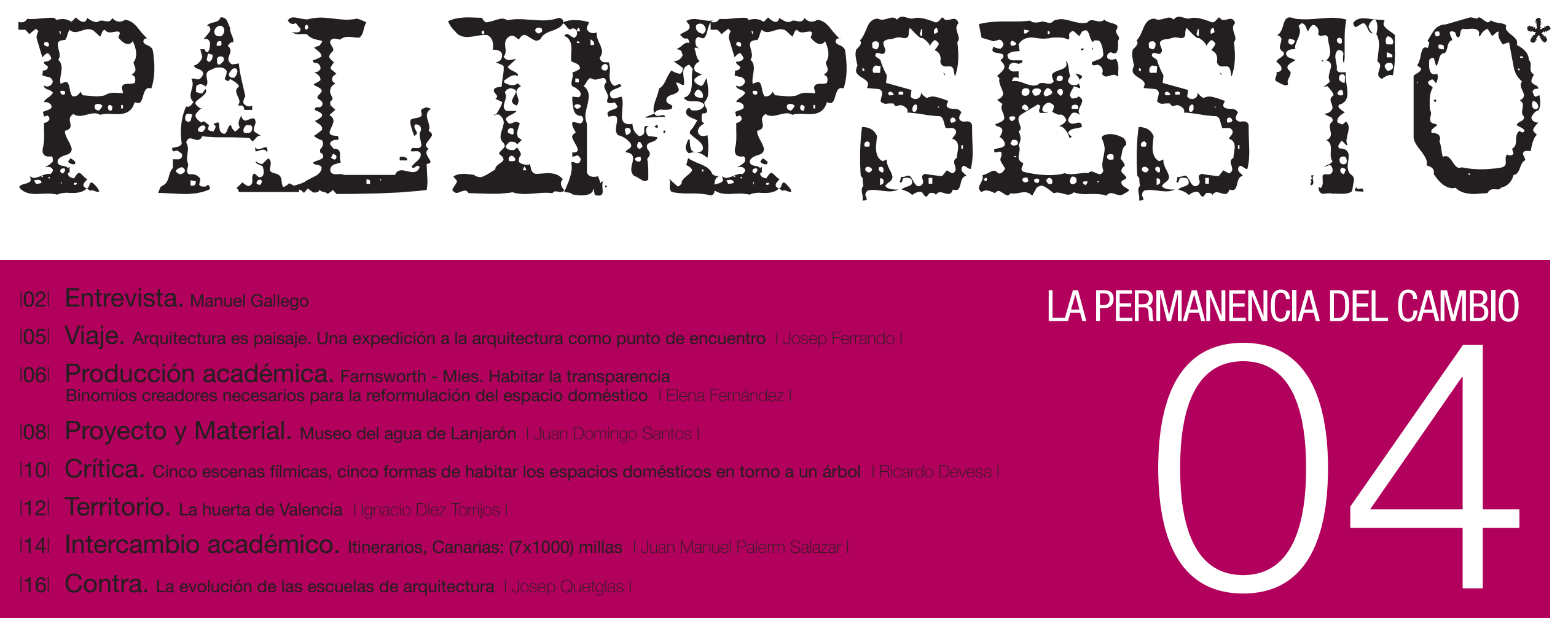

4 EUR www.catedrablancabarcelona.com Marzo 2012

Edita CÁTEDRA BLANCA

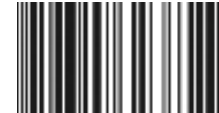

Cinco escenas fílmicas Cinco formas de habitar los espacios domésticos en torno a un árbol

Ricardo Devesa

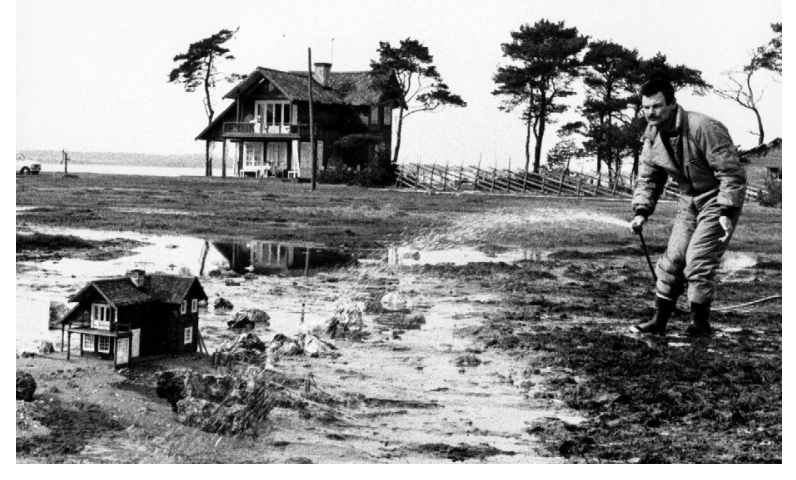

El río (The River), Jean Renoir, 1951. Principios de verano (Bakushu), Yasujiro Ozu, 1951. La noche (La notte), Michelangelo Antonioni, 1962. Sacrificio (Offret). Andrei Tarkovski, 1986. Las cenizas de la luz (Beed-e majnoon -Weeping Wi(low), Majid Majidi, 2005

A través de estas películas, Ricardo Devesa analiza, en sus propias palabras, cinco casos en los que los árboles, a través de la mirada de los cineastas, presentan y representan las vidas narradas en los filmes.

\section{Entrevista a Manuel Gallego}

Manuel Gallego (O Carballiño, 1936) obtiene el título de Arquitecto por la Escuela Técnica (1963). Su formación se completa como discípulo y colaborador de Alejandro de la Sota, con quien le une una relación profesional, intelectual y personal que se prolonga hasta la

muerte del maestro.
Desde el año 2002 es catedrático del Departamento de Proyectos Arquitectónicos y Urbanismo de la Escuela Superior de Arquitectura de la Universidad de A Coruña, en la que ha ejercido la docencia desde 1978. Entre las numerosas menciones y galardones que ha recibido por su dilatada trayectoria quécicio Nacional de Arquitectura (1907) y la Medala de Oro del Consejo Superior de Colegios de Arquitectos de España 2010.

Arquitectos de Españ 2010. Entre el gran numero de obras que ha desarollado destacan las viviendas unifamiliares en Paderne (1984-89), la rehabilitación de la Casona dos Lemos de Chantada como Casa de Cultura (1987-90), el Museo de Bellas Artes de A Coruña (1988-95), la vivienda unifamiliar en Veigue (1988-91) y la residencia oficial del Presidente de la Xunta de Galicia (1999-2002).

De estos y otros proyectos se habla a lo largo de esta entrevista, en la que Manuel Gallego expone su visión sobre el aprendizaje, la dimensión política y social, el dibujo y la construcción de la arquitectura. Con especial énfasis se aborda la relación entre la arquitectura y la naturaleza, así como las nuevas perspectivas de la profesión dentro de la actual coyuntura.

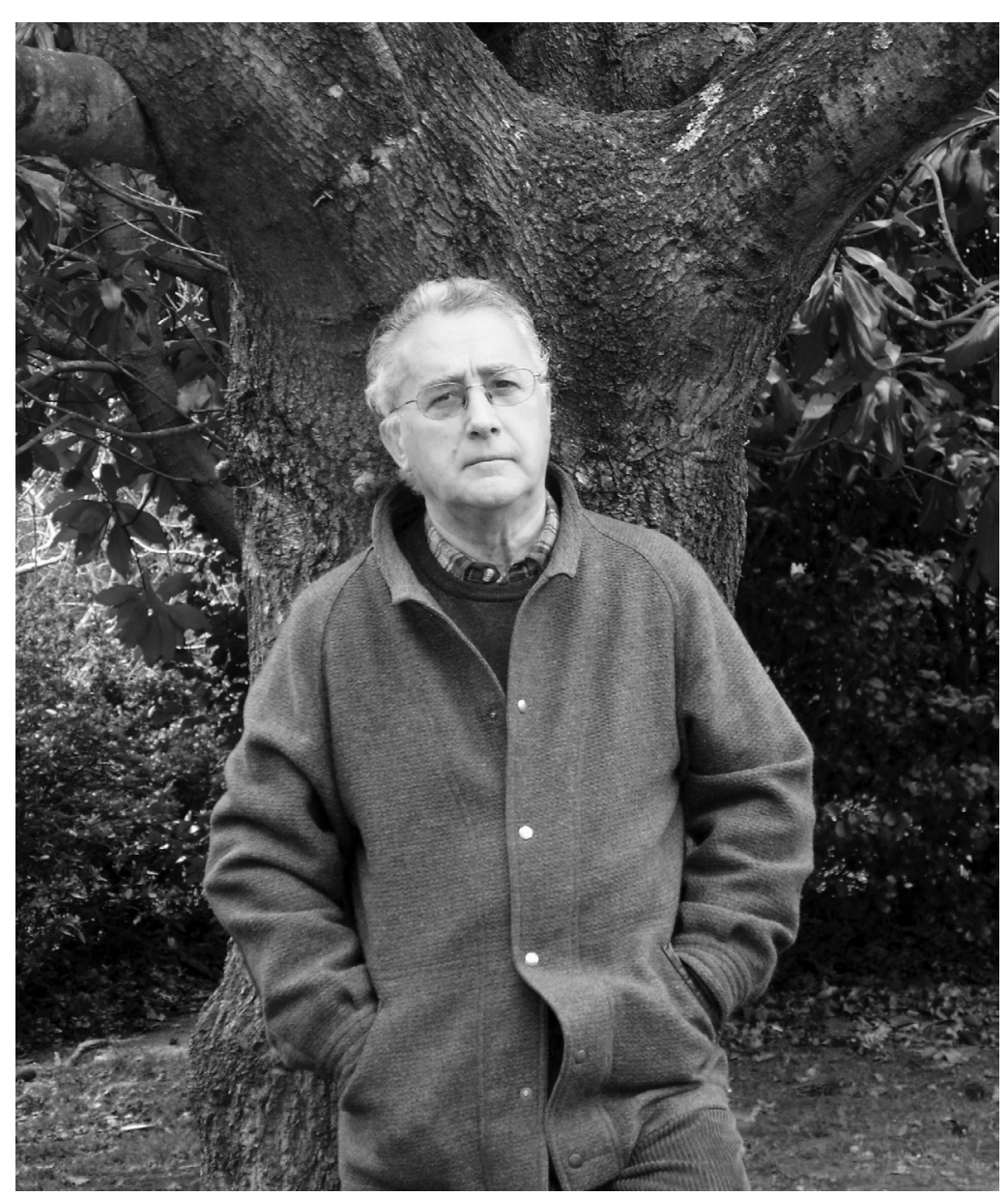

La huerta de Valencia Ignacio Díez Torrijos
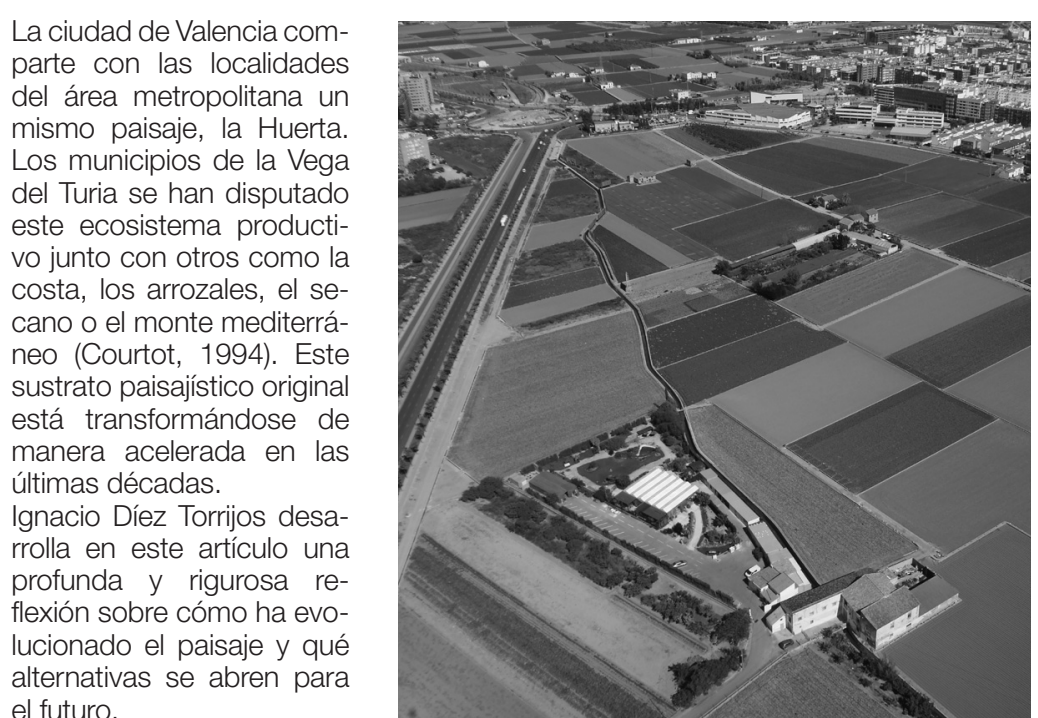